\title{
DO ESTADO SOCIAL A RETOMADA (OSTENSIVA) DO PROJETO DE ESTADO NEOLIBERAL NO BRASIL E SEUS IMPACTOS NO DIREITO HUMANO E FUNDAMENTAL AO TRABALHO
}

\author{
FROM THE SOCIAL STATE TO THE (OSTENSIVE) RESUME OF THE DRAFT \\ NEOLIBERAL STATE IN BRAZIL AND ITS IMPACTS ON HUMAN AND \\ FUNDAMENTAL LAW AT WORK
}

\author{
Luciana Aboim ${ }^{1}$ \\ Lourenço de Miranda Freire Neto ${ }^{2}$ \\ Rodrigo Teixeira Matos ${ }^{3}$
}

\begin{abstract}
RESUMO
O que se observa na atualidade, em específico no Brasil, é a retomada (agora de maneira ostensiva) do projeto de Estado Neoliberal em detrimento da concepção de Estado Social, sendo que, sob o viés das relações de trabalho, denota-se a adoção de um projeto de governo que visa ampliar a liberdade de empresas, retirar direitos sociais e fragilizar instituições públicas e privadas (com munus público) que atuam nas relações sociais e na promoção de políticas públicas, sendo a análise deste contexto, o objeto precípuo deste trabalho, sob um
\end{abstract}

\footnotetext{
${ }^{1}$ Pós-doutora em Direito pela Universidade Federal da Bahia e pela Università Degli Studi G. dAnnunzio (Italia). Doutora em Direito do Trabalho pela Faculdade de Direito da Universidade de São Paulo. Mestre em Direito do Trabalho. Especialista em Direito do Trabalho e em Direito Processual Civil, pela Pontifícia Universidade Católica de São Paulo. Professora Associada da Universidade Federal de Sergipe. Coordenadora do Programa de Pós-Graduação "stricto sensu" em Direito da Universidade Federal de Sergipe. Avaliadora de Instituição de Ensino Superior do INEP/MEC.

2 Advogado e Professor. Doutorando em Direito Político e Econômico pela Universidade Presbiteriana Mackenzie. Mestre em Direito pela Universidade Católica de Pernambuco. Bacharel em Direito pela Universidade Federal da Paraíba. Professor da Universidade Federal da Paraíba - licenciado para tratar de assuntos particulares. Professor Assistente e Coordenador de Educação Continuada na Universidade Presbiteriana Mackenzie. Atua nas áreas de direito médico, direito da saúde (seguridade social), direito constitucional, direito civil, direito processual civil e prática jurídica civil. Integrante do Conselho Editorial da Juruá Editora. Parecerista da Revista Internacional de Direito do Conselho Internacional de Estudos Contemporâneos em Pós-Graduação. Membro do Comitê de Ética em Pesquisa do Centro de Ciências Médicas da Universidade Federal da Paraíba. Foi Presidente da Comissão de Direito Médico-Hospitalar e Planos de Saúde (2013-2016) e Ouvidor-Geral Adjunto (2018) da Ordem dos Advogados do Brasil Seccional da Paraíba.

${ }^{3}$ Mestrando em Direitos Humanos e Políticas Públicas pela PUC/PR, Graduado em Direito e Pós-Graduado em Direito do Trabalho pela mesma instituição e Advogado Trabalhista.
} 
enfoque interdisciplinar. Para a pesquisa, utiliza-se uma abordagem qualitativa, com método dedutivo e pesquisas orientadas em fontes bibliográficas e primárias.

Palavras-chave: Estado; Liberal; Social; Neoliberal; Trabalho.

\begin{abstract}
What is currently observed, particularly in Brazil, is the resumption (now ostensibly) of the Neoliberal State project to the detriment of the conception of the Social State. It aims to expand the freedom of companies, remove social rights and weaken public and private institutions (with public munus) that act in social relations and the promotion of public policies. For the research, we use a qualitative approach, with deductive method and research oriented in bibliographic and primary sources.
\end{abstract}

Keywords: State; Liberal; Social; Neoliberal; Job.

\title{
1. A REVOLUÇÃO INDUSTRIAL E AS CONDIÇÕES DE TRABALHO
}

Um dos grandes marcos temporais da humanidade ocorreu na idade moderna - a revolução industrial, que teve como principais consequências, a criação do trabalho assalariado e o surgimento do direito do trabalho. Durante este período da revolução, emergiu a classe social trabalhadora (proletariado), bem como ocorreu o desenvolvimento da classe burguesa e a instauração do capitalismo.

A partir de então sobrevieram inúmeros conflitos envolvendo a classe trabalhadora (proletariado) e a classe burguesa, em decorrência da constante tensão e luta entre capital x trabalho assalariado, e por conta, também, do avanço do capitalismo - diretamente relacionada aos meios de produção - como forma de imposição de uma estrutura social exploratória.

Não se pode deixar a margem, que neste momento histórico, prevalece a concepção de Estado Liberal, sob o pressuposto de afastamento da intervenção estatal e do entendimento de que o mercado poderia se autorregular, no entendimento idealista e romântico de Adam Smith, de que a separação do Estado da Economia permitiria a ampliação do mercado de trabalho, além de uma melhor qualificação dos indivíduos. (SMITH, 2015) 
Mas o que se observou, foi o latente crescimento da burguesia concorrencial capitalista, com objetivo precípuo de lucro e mais valia, incorrendo em condições prejudiciais aos trabalhadores, submissos aos interesses dos indivíduos detentores dos meios produtivos, exasperando-se a tensão entre o capital e o trabalho.

As tensões entre as classes se agravam com a organização dos trabalhadores em associações, e com a implementação de inúmeras reinvindicações, em especial, quanto à limitação da jornada de trabalho.

Em geral, os trabalhadores eram submetidos a exaustivas jornadas de 14 a 16 horas, com intervalos mínimos de descanso, e sem que tivessem oportunidades de desenvolver seu intelecto, vivendo em condições não condizentes com as necessidades mínimas humanas, na grande maioria das vezes, habitavam as próprias instalações do local onde trabalhavam.

Não havia uma legislação que regulamentasse as questões relacionadas ao trabalho, desta feita, os "patrões" estabeleciam excessivas jornadas de trabalho, na busca incessante pelo lucro e pela mais valia.

Um dos fatores que contribui para o aumento da jornada de trabalho foi à invenção do lampião a gás em 1792, por Willian Murdock. Com a utilização da iluminação artificial, surgiu a possibilidade de se estender à jornada além do pôr do sol, estabelecendo assim, jornadas noturnas.

Costumeiramente a jornada de trabalho era delimitada pelo toque da campainha das empresas que soava 15 minutos antes do amanhecer, determinando o início da jornada. A jornada diária mínima era de 12 horas, destacando-se que a jornada média era de 14 a 16 horas.

Em meados do século XIX, a jornada de trabalho desempenhada nas províncias era de 12 horas, enquanto em Paris, a média diária era de 11 horas, evidentemente que estas jornadas eram variáveis, conforme a especificidade do labor.

A organização dos trabalhadores em associações, fomenta o surgimento de uma consciência de classe, que teria por escopo reivindicar e exigir condições dignas aos trabalhadores.

Em especial, destaca-se a reivindicação dos trabalhadores ingleses por jornadas diárias de oito horas, sendo fato costumeiro que referidos trabalhadores ecoassem cânticos contestadores: eight hours to work, eight hours to play, eight hours to sleep, eight shillings a day. (NASCIMENTO, 2005, p. 333). 
Proliferam inúmeros focos de sindicatos, principalmente na Inglaterra, entretanto, estes movimentos sindicais eram considerados clandestinos e à margem da sociedade da época, por conta da Lei Le Chapelier, que vedava qualquer forma de associação ou mesmo de reunião.

Editada em 1802 a Lei de Peel limitou a jornada de trabalho em 12 horas, excluindo os intervalos para a refeição, e ainda, vedou a prolongação do trabalho após as 21 horas e o início antes das 6 horas da manhã.

O reconhecimento oficial do movimento sindical ocorreu em 1871, com a edição da Lei dos Sindicatos na Inglaterra. A França, por sua vez, editou a Lei Waldeck - Rousseau que reconheceu personalidade civil aos sindicatos e, por conseguinte derrogou a Lei Le Chapelier.

A igreja, anteriormente alheia às questões da classe trabalhadora, apresenta como primeiro documento a questionar as condições de trabalho, a encíclica Rerum Novarum, escrita pelo Papa Leão XIII. Este documento trouxe a tríade, limitação do tempo de trabalho em razão dos fundamentos biológicos, econômicos e sociais.

Após a elaboração desta encíclica, e com a crescente proliferação dos sindicatos e o consequente aumento dos conflitos entre as classes sociais, surgiu a necessidade de adoção, por parte dos Estados de uma política intervencionista, sobreposta ao liberalismo, avanço, assim, a ideia de Estado Social de Direito e do desenvolvimento do movimento constitucionalista.

\section{DA CONCEPÇÃO DE ESTADO LIBERAL À PERSPECTIVA DE ESTADO SOCIAL}

A par da elaboração da Encíclica Rerum Novarum, escrita pelo Papa Leão XIII, que demonstra, de forma expressa, a preocupação da Igreja Católica com as condições de trabalho e com a classe trabalhadora, bem como diante da sublevação de conflitos entre trabalhadores (trabalho) e burgueses (capital) potencializados pela proliferação de Sindicatos, emerge a necessidade de adoção, por parte dos Estados de uma política intervencionista, sobreposta ao liberalismo.

Ao passo de que na concepção e formação do Estado Liberal emergem fundamentos embasados nos pensamentos de Rousseau (sob um viés de maior concentração política), em especial de sua Magnum opus, Do contrato social, que analisa a objeção da burguesia 
capitalista, crescente, frente ao status quo (monarquias absolutistas) do século XVIII, é inafastável para o estudo das concepções de Estado Social a feição cientifica introduzida por Karl Marx à cerca do socialismo (ulterior socialismo utópico), partindo do oposicionismo econômico de classes (operários x burgueses) no século $\mathrm{XX}$, desde os primórdios de seus Manuscritos econômico-filosóficos à sua grande obra O capital (BONAVIDES, 2007, p. 165 a 181).

Em que pese todos os anteriores ideais liberais, Marx vislumbrou que o ser humano do século XX encontrava-se escravizando, diante do assenhoramento econômico de uma classe econômica dominante. Toda a sua obra volta-se à luta de classes, com a defesa de uma necessária revolução que impusesse a tomada (violenta) do poder pela classe operária, em desfavor da classe burguesa e capitalista, então opressora.

Para além da teoria marxista, cabe traçar a distinção entre o conceito de Estado Socialista que pretendia extirpar o Estado da burguesia e sua economia capitalista, com a já mencionada tomada do poder pela classe operária, e a concepção moderada de Estado Social que objetiva uma mediação com o Estado Liberal. O conceito de Estado Social transita pela necessária mudança do Estado Liberal com a redução do predomínio da burguesia e a harmonização entre o trabalho e o capital, prevalecendo o equilíbrio entre todas as classes. Neste sentido o Estado Social pode ser compreendido como o meio do caminho para o Estado Socialista, mas, por certo, o seu caminho apropriado é o estabelecimento de um Estado Social Democrático, visto que o estabelecimento e ampliação dos direitos políticos a todas as classes, permite a consecução do Estado como transformador social.

De forma ampla, o Estado Social é travestido de diversas roupagens e recebe variadas denominações, sendo tratado como o Estado assistencial, Estado providência, Welfare State, Estado de bem-estar, Estado de partidos, Estado de associações e Estado Administrativo, sendo de maior expressividade o estabelecimento de novas relações entre o Estado (Social), cidadãos e a sociedade, com a garantia da integração existencial não limitada a aos direitos e liberdades clássicos (amalgamado no direito a propriedade), expandida, assim, para as questões sociais e os direitos de segunda geração (NOVAIS, 2006, p. 187 a 188).

Com o fortalecimento das massas, o Estado Social passa a intervir sobre domínios fundamentais a existência humana e que pertenciam a iniciativa individual, como o trabalho, previdência, educação, moradia, regulação da economia, dentre outros. Não se pode deixar à margem, entretanto, que a tentativa do Estado em concorrer com a iniciativa privada, sob o 
domínio produtivo - instalação, manutenção e exploração de meios produtivos - aproxima o Estado Social do Estado Socialista, o que depõe contra o equilíbrio de classes.

O avanço da ideia de Estado Social fortalece a necessidade de regulação da intervenção do Estado, incorrendo no desenvolvimento de um movimento constitucionalista, com especial destaque a Carta Política mexicana de 1917 que foi a primeira constituição de Estado a atribuir aos direitos trabalhistas à qualidade de direitos fundamentais, incorporando vários direitos sociais, juntamente com as liberdades individuais e os direitos políticos. É considerada a primeira constituição social do mundo.

Entretanto, essa tentativa pacificadora e conceitual do Estado Social, permite a aproximação do Estado com regimes políticos opostos, seja a democracia ou mesmo o fascismo e o nacional-socialismo. Em período próximo a emersão do preâmbulo ideal de Estado Social e do desenvolvimento do movimento constitucionalista, eclodiu a Primeira Guerra Mundial, travada em campos de batalhas e trincheiras. Mas em continuidade ao desenvolvimento da ideia de Estado Social e da constitucionalização da intervenção estatal sobre domínios fundamentais a existência humana, destaca-se a Constituição de Weimar, em 1919, trilhou a mesma via da Carta mexicana, em um momento, pós Primeira Guerra Mundial, trouxe como ponto de grande relevância a consagração dos direitos sociais de segunda dimensão (trabalho, educação, cultura, previdência), primando pela reestruturação do Estado em prol da Sociedade, e não somente em detrimento do indivíduo (MORAES, 2018, p. 3 e 4$)$.

Como o advento do Tratado de Versalhes que estabeleceu o fim da Primeira Guerra Mundial, e como parte do respectivo tratado, é criada a Liga das Nações, em 28 de junho de 1919, sendo está constituída como uma organização internacional com sede em Genebra, da Suíça, dispondo do objetivo principal de garantir a paz. E também, como parte do Tratado de Versalhes, já considerando a elevação do direito ao trabalho como direito fundamental a existência humana, é fundada, em 1919, a Organização Internacional do Trabalho (OIT) com o objetivo precípuo de promover a justiça social.

Já em seu preâmbulo, por intermédio da primeira Conferência Internacional do Trabalho, a OIT adotou seis convenções, sendo que a primeira, de forma inconteste, reconheceu a necessidade de limitação da jornada de trabalho a 8 horas diárias e 48 horas semanais, como uma das principais reivindicações do movimentos sindicais e operários, sendo, ainda, que as demais convenções adotadas tratam sobre: à proteção à maternidade, à 
luta contra o desemprego, à definição da idade mínima de 14 anos para o trabalho na indústria e à proibição do trabalho noturno de mulheres e menores de 18 anos. ${ }^{4}$

Ainda que passadas as experiências do passado e mesmo com a criação de organizações que detinham o objetivo principal de manter a paz (em especial à Liga das Nações), em idos de 1939 eclodiu um novo conflito bélico global - Segunda Guerra Mundial -, que perdurou até 1945, e que segregou o mundo entre dois grupos globais opostos, Aliados (capitaneados pelos Estados Unidos, União Soviética, Reino Unido e China) e o Eixo (Alemanha, Itália e Japão), sendo que, ao contrário da Primeira Guerra Mundial, os combates não se limitaram às trincheiras, estendendo-se a muitas outras áreas, deflagrando a morte de inúmeros civis (holocausto e lançamento de bombas atômicas).

Com o insucesso da Liga das Nações no seu objetivo de manter a paz, e após o término da Segunda Guerra Mundial, é criada a Organização das Nações Unidas (ONU) em 24 de outubro de 1945, que tem seus objetivos expandidos para além da manutenção da segurança e da paz mundial, cuidando de promover os direitos humanos, auxiliar no desenvolvimento econômico e no progresso social, proteger o meio ambiente e prover ajuda humanitária em casos de fome, desastres naturais e conflitos armados. ${ }^{5}$ A partir da criação da ONU a Organização Internacional do Trabalho (OIT) torna-se a primeira agência especializada, em idos de 1946, reforçando o reconhecimento do trabalho como um direito fundamental à existência humana, e como meio de manutenção da paz.

\section{A DECLARAÇÃO UNIVERSAL DOS DIREITOS HUMANOS, A CARTA INTERNACIONAL DE DIREITOS HUMANOS E O DIREITO AO TRABALHO}

Em resposta às infindáveis atrocidades cometidas, em especial, no decorrer das duas grandes guerras mundiais a ONU e seus países membros projetam a elaboração de um documento que estabelecesse um marco na evolução dos direitos humanos (decorrente da construção evolutiva) visando garantir a todo ser humano condições mínimas de sobrevivência e crescimento em ambiente de respeito e paz, igualdade e liberdade. Ainda que já passadas duas grandes guerras mundiais, o momento era de aquecimento de disputas

\footnotetext{
${ }^{4}$ https://www.ilo.org/brasilia/conheca-a-oit/hist\%C3\%B3ria/lang--pt/index.htm

${ }^{5}$ https://nacoesunidas.org/conheca/historia/
} 
estratégicas e batalhas indiretas entre os Estados Unidos da América e a União Soviética (Conflitos de ordem política, militar, tecnológica, econômica, social e ideológica e que se estendeu desde o fim da segunda guerra mundial em 1945 até a extinção da União Soviética em 1991, conhecida como Guerra Fria). ${ }^{6}$

A elaboração da Declaração Universal dos Direitos Humanos ficou a cargo de um comitê formado a partir de um Secretariado organizado pela ONU, sendo que os trabalhados foram realizados no período de 1946 a 1948, destacando os seguintes membros do mencionado comitê: Eleonor Roosevelt (Estados Unidos), Peng Chun Chang (Taiwan), Charles Dukes (Reino Unido), Alexander Bogomolov (União Soviética), John Peters (Canadá), Hernán Santa Cruz (Chile), René Cassin (França), William Hodgson (Austrália) e Charles Malik (Líbano).

No período de aprovação e elaboração da Declaração, a Comissão foi presidida por Eleonor Roosevelt, sendo que, em grande medida, as contribuições em um documento integrado, com sentido de aplicação universal, foram reunidas por René Cassin, que em 1968 recebeu o Prêmio Nobel da Paz. O jornalista e escritor brasileiro Austregésilo de Athayde, colaborou na elaboração da Declaração.

A Declaração foi proclamada pela Assembleia Geral da ONU em Paris, no dia 10 de dezembro de 1948, por intermédio da Resolução 217-A, com aprovação de 48 Estados, nenhum voto contra, 8 abstenções (a maior parte do bloco soviético - Bielorrúsia, Tchecoslováquia, Polônia, Ucrânia, União Soviética e Iugoslávia -, além da África do Sul e Arábia Saudita), sendo, ainda, que 2 delegações não votaram (Honduras e Iêmen). A que se destacar que o Brasil foi um dos 48 países que votaram a favor da Declaração.

O objetivo precípuo do documento é a consolidação de uma ética universal a ser seguida pelos Estados, com o significado de um "código" e plataforma comum de ação (norma) a ser alcançada por todos os povos e nações, fundamentado, inclusive, pela inexistência de qualquer questionamento ou de reserva pelos Estados - aos princípios da Declaração -, ou mesmo de voto contrário as suas disposições.

A Declaração é composta por um preâmbulo e 30 artigos que versam sobre questões relacionadas à liberdade, igualdade, dignidade, alimentação, moradia e ensino, sendo o documento mais traduzido do mundo, sendo que, atualmente, alcança 500 idiomas e dialetos.

\footnotetext{
${ }^{6}$ Conflitos de ordem política, militar, tecnológica, econômica, social e ideológica e que se estendeu desde o fim da segunda guerra mundial em 1945 até a extinção da União Soviética em 1991, conhecida como Guerra Fria.
} 
Atualmente, a ONU é composta por 193 países-membros, sendo todos signatários da Declaração. $^{7}$

Dentre as principais características da Declaração, destaca-se a sua amplitude, considerando-se que o documento reveste de um conjunto de direitos e faculdades necessários ao desenvolvimento físico, moral e intelectual do ser humano, alcançando assim a todos, sendo requisito, apenas, a condição de pessoa humana para a efetiva subsunção.

A Declaração goza, também, da característica de universalidade, posto que é inerente a todos os seres humanos, independentemente de raça, gênero, religião, Estado, ou o que for.

Há que se destacar, ainda, a indivisibilidade e interdependência da Declaração, no sentido de que o seu conteúdo afasta qualquer dicotomia entre o direito à liberdade e o direito à igualdade, bem como extirpa a ideia da suposta existência de gerações de direitos humanos.

Quanto à natureza jurídica da declaração, em uma primeira análise, entende-se que o documento não teria força de lei, em razão de não ser um tratado, mas sim uma resolução adotada pela Assembleia Geral da ONU. Entretanto, para alguns autores, como Flávia Piovesan, a Declaração apresenta força jurídica obrigacional e vinculante, ao passo de que constituiu a interpretação autorizada da expressão "direitos humanos" prevista nos $\operatorname{artigos~} 1^{\circ} \mathrm{e}$ 55 da Carta das Nações Unidas, sendo que por intermédio deste documento, os Estados assumem o compromisso de assegurar o respeito universal e efetivo aos direitos humanos (PIOVESAN, 2018, p. 237 a 242).

A par deste primeiro entendimento, há que se destacar, ainda, que a Declaração detém natureza de direito costumeiro internacional e de princípio geral do Direito Internacional, sendo fonte de criação para outros documentos internacionais, impactando, ainda, de forma direta intra-Estados, com a incorporação dos direitos nela previstos às constituições nacionais.

Neste sentido, podemos considerar que os direitos humanos diferem dos direitos fundamentos, em linhas gerais, apenas, na sua dimensão, no sentido de que os direitos humanos alcançam a dimensão internacional, enquanto que os direitos fundamentais vinculam-se a dimensão interna do Estado, sem, por óbvio, deixar de considerar as eventuais diferenças materiais que possam ser vislumbradas em destacadas dimensões.

Fato inexorável a ser considerado é o objetivo da Declaração Universal dos Direitos Humanos de fixação de um "código" de atuação e conduta a ser seguido por todos os Estados,

7 NAÇÕES UNIDAS, ONU. Declaração Universal dos Direitos Humanos. Disponível em: <https://nacoesunidas.org/direitoshumanos/declaracao>. Acesso em: 4 de novembro de 2019. 
como fator preponderante na garantia de uma vida digna a todos os seres humanos - e na observância de todos os direitos inerentes - independentemente de raça, sexo, nacionalidade, etnia, idioma, religião ou qualquer outra condição -, e como forma de manutenção da harmonia e paz na sociedade e, ainda, para que subsista a condição de existência e preservação de um poder soberano que irradie do povo, e em prol deste. Enfim, Democracia, Paz, e Justiça Social.

Sem subestimar todo o arcabouço histórico e legislativo pretérito destaca-se, como marco inicial do regime internacional de direitos humanos, a Declaração Universal dos Direitos Humanos adotada pela Assembleia-Geral da ONU em 1948, que reflete o ideal comum da sociedade mundial, em um momento pós regimes totalitaristas - que sob qualquer hipótese devem ser esquecidos para que, até mesmo, nunca se repitam (sob qualquer pretexto) - que já em seu artigo XXIII, assegurou o trabalho como direito humano com a previsão de garantias e direitos inerentes.

Em continuação ao processo de reconhecimento e afirmação dos direitos humanos, nos idos de 1966, foram aprovados dois pactos pela ONU, com vigência 10 anos depois: Pacto Internacional sobre Direitos Civis e Políticos (PIDCP); e Pacto Internacional sobre Direitos Econômicos, Sociais e Culturais (PIDESC). Em especial, o PIDESC trata, de forma mais especial, sobre: o direito ao trabalho e de condições justas e favoráveis ao trabalho, liberdade de constituição ou associação a sindicatos; previdência social, padrões adequados de vida, saúde, educação, descanso e lazer; e a participar da vida cultural e de atividades criativas. No tocante ao trabalho, destacam-se os artigos $6^{\circ}, 7^{\circ}$ e $8^{\circ}$ do PIDESC $^{8}$ :

A Declaração Universal dos Direitos Humanos, juntamente com o PIDCP e PIDESC, formam a Carta Internacional dos Direitos Humanos, já complementados por sete tratados adicionais da ONU (que acrescentam fundamentos e descrições).

Sempre importante destacar que o direito ao trabalho como direito humano que é, assegura a todas as pessoas uma inerente dignidade, bem como resguarda direitos iguais e inalienáveis, sob a forma de prerrogativa, afastando-se qualquer entendimento de necessária concessão neste sentido. Não por outro motivo que instrumentos internacionais de direitos humanos versam sobre o reconhecimento de direitos humanos e não sobre a sua criação, posta que esta última conceituação seria totalmente equivocada.

\footnotetext{
${ }^{8}$ GOVERNO DO BRASIL, PRESIDÊNCIA DA REPÚBLICA, PLANALTO. Decreto $n^{\circ} 591$, de 6 de julho de 1992 (promulgação do PIDESC).

Disponível em: <http://www.planalto.gov.br/ccivil_03/decreto/1990-1994/d0591.htm〉. Acesso em: 05 de julho de 2019.
} 


\section{O DIREITO HUMANO E FUNDAMENTAL AO TRABALHO NA CONSTITUIÇÃO FEDERAL BRASILEIRA DE 1988}

Em paralelo a marcha de reconhecimento do direito humano ao trabalho, que se distingue do direito fundamental ao trabalho, em linhas gerais pela dimensão internacional daquele em contrapartida a dimensão interna deste, houve o início do processo de redemocratização do Brasil, após o regime de ditadura militar que perdurou de 1964 a 1985, com especial destaque a necessária promulgação da Constituição Federal de 1988, conhecida como constituição cidadã, que sepultou a execrável ditadura militar e restabeleceu a indispensável democracia, reconhecendo direitos e garantias fundamentais - com especial destaque a previsão dos direitos sociais, dentre eles o direito ao trabalho -, sendo a carta constituinte formada por nove títulos temáticos, e que se encerra com o Ato das Disposições Constitucionais Transitórias: Título I - Princípios Fundamentais; Título II - Direitos e Garantias Fundamentais; Título III - Organização do Estado; Título IV - Organização dos Poderes; Título V - Defesa do Estado e das Instituições Democráticas; Título VI - Tributação e Orçamento; Título VII - Ordem Econômica e Financeira; Título VIII - Ordem Social; Título IX - Disposições Constitucionais Gerais.

A Constituição Federal de 1988 tendo reconhecido a relevância da matéria içou os direitos dos trabalhadores à hierarquia máxima de seus preceitos, aduzindo-os como um rol de preceitos fundamentais na ordem dos direitos humanos de segunda dimensão. A valorização do trabalho humano é reiteradamente ressaltada pela Constituição Federal de 1988, desde o seu preâmbulo, passando pela elucidação dos princípios fundamentais - artigos $1^{\circ}$, III e IV, e $3^{\circ}$ - (Título I), detalhadamente tratada dos direitos e garantias fundamentais (Título II) por intermédio dos artigos $6^{\circ}$ e $7^{\circ}$ (direitos sociais), e por fim, destacada nos artigos 170 (Título VII - da Ordem Econômica e Financeira, Capitulo I - dos Princípios Gerais da Atividade Econômica) e 193 (Título VIII - da Ordem Social, Capitulo I - Disposição Geral).

De forma contemporânea à promulgação da Constituição Federal de 1988, destacamse duas encíclicas do Pontíficie João Paulo II, Laborem Exercens (1981) e Solicitudo Rei Socialis (1987), que demonstram a preocupação da Igreja com: a relação do trabalho para o 
homem e não o homem para o trabalho; e a centralidade do homem (o homem como sujeito e não objeto do trabalho); respectivamente.

Como já destacado, o direito ao trabalho foi elevado ao patamar de um direito humano e fundamental, previsto na Constituição Federal de 1988 no capítulo dos direitos sociais (Capítulo II) e no título de direito e garantias fundamentais (Título II), sendo cláusula pétrea da precitada carta magna, como expressamente disposto no artigo $60, \S 4^{\circ}$, inciso IV, do diploma, não sendo, portanto, passível de alteração.

\section{A RETOMADA DO CONCEITO LIBERAL E O AVANÇO DO PROJETO DE ESTADO NEOLIBERAL DE FORMA OSTENSIVA}

Nunca desútil recordar o momento histórico de formação da Carta Internacional dos Direitos Humanos - com o reconhecimento do direito humano ao trabalho (dimensão global) se deu no ápice das disputas estratégicas e batalhas indiretas entre os Estados Unidos da América e a União Soviética na então denominada guerra fria, em que se seguiram conflitos de ordem política, militar, tecnológica, econômica, social e ideológica e que se estendeu desde o fim da segunda guerra mundial (1945) até a extinção da União Soviética em 1991, sendo, ainda, que no precitado período (já em seus derradeiros anos), ocorreu a promulgação da Constituição Federal do Brasil de 1988, que reconheceu o direito fundamental ao trabalho (dimensão Estatal).

Indelével o esclarecimento de que sob o viés histórico, após o fim das duas grandes guerras mundiais e sob a hegemonia das duas grandes potências "vencedoras", Estados Unidos e União Soviética, que se opunham, principalmente, acerca da ideologia econômica (capitalismo x socialismo), sucedeu-se uma polarização global, com a segregação do Bloco do Ocidente e Bloco Soviético, que se deu com o ápice das disputas estratégicas e batalhas indiretas entre os Estados Unidos da América e a União Soviética na então denominada Guerra Fria, em que se seguiram conflitos de ordem política, militar, tecnológica, econômica, social e ideológica e que perdurou do fim da Segunda Guerra Mundial (1945) até a extinção da União Soviética em 1991, muito bem elucidados por Vladimir Oliveira da Silveira e Maria Mendez Rocasolano (SILVEIRA, 2010, p. 153 e 154).

Neste contexto, pós Segunda Guerra Mundial e início da Guerra Fria, em especial, nas décadas de 1950 e 1960, as principais potências econômicas do Ocidente, apropriaram-se 
da concepção de Estado Social, como uma opção entre o Liberalismo (ideais da revolução francesa iniciada em 1789) e o Socialismo (em grande medida espraiado pela Revolução Russa de 1917 e a ascensão do Partido Bolchevique), adotando, a partir de então, os preceitos da teoria keynesiana, que, em linhas gerais, opõe-se as conceitos liberais, pressupondo a necessidade do Estado agir no controle da economia como meio de garantir as condições de empregabilidade, atuando como agente controlador do "espírito animal" do empresariado (KEYNES, 1996). A doutrina keynesiana entrou em declínio na década de 1970, sob forte influência de dificuldades econômicas que atingiram os Estados Unidos e o Reino Unido, e massivas críticas de economistas liberais, destacando a Escola de Chicago e atuação de Milton Friedman e George Stigler.

Concomitantemente ao período final da já mencionada guerra fria, no fim dos anos 70 e início dos anos 80, emerge, na supremacia Ocidental, a doutrina neoliberal (retomada de ideais liberais), pautada em um movimento "favorável" ao afastamento da participação do estado na economia, mediante a adoção de um conjunto de ideias políticas/econômicas capitalistas, na busca pela liberdade de comércio (livre mercado) sob a justificativa de garantir-se o crescimento e desenvolvimento econômico e social das nações. ${ }^{9}$

No campo político, sob a concepção neoliberal, destacou-se a eleição da PrimeiraMinistra do Reino Unido Margareth Thatcher, em 1979 e do Presidente dos Estados Unidos Ronald Regan, em 1980, que, sob a justificativa de promover e garantir a liberdade das capacidades empreendedoras individuais com a institucionalização de sólidas estruturas de proteção à propriedade privada, ao livre comércio e mercado, subsumiram a missão de restringir o poder do trabalho e da atuação dos sindicatos, especialmente no Reino Unido, quanto a esta última projeção de atribuição.

Sob a égide da supremacia norte-americana, e de suas instituições financeiras, foram formuladas medidas econômicas em grande medida impostas ao demais países do continente americano, em idos de 1989, então denominadas de Consenso de Washington, com o objetivo precípuo de orquestrar e hegemonizar a doutrina neoliberal no continente. Em especial, destaca-se na América Latina a ditadura de Augusto Pinochet, no Chile a partir de 1973, e a eleição dos Presidentes: Carlos Salinas, no México em 1988; Carlos Menem, na Argentina em 1989; Fernando Collor, no Brasil em 1989; Carlos Andrés Perez, na Venezuela em 1988; e Alberto Fujimori, no Peru em 1990 (convertido em regime autoritário, e, na sequência, ditatorial).

\footnotetext{
9 Destaca-se a Escola de Economia de Chicago com George Joseph Stigler e Milton Friedman, e a Escola Austríaca de pensamento econômico com Friedrich August von Hayek e Ludwing Heinrich Edler von Mises.
} 
Em paralelo ao avanço neoliberal, decorreu a crise e o esfacelamento do regime soviético, motivo pela ausência de democracia e por uma grande crise econômica, tendo como grande marco à queda do Muro de Berlim, em 1989, que de uma maneira simbólica, no aspecto global, e forma direta, para a Alemanha, pós-fim a segregação entre Ocidente e Oriente, encaminhando a Guerra Fria ao seu fim (inclusive, com a independência das repúblicas soviéticas), que se consolidou em 1991, com a dissolução da União Soviética.

A partir de então, houve a assentamento da hegemonia dos Estados Unidos da América, e do capitalismo fundamentado na doutrina neoliberal, em se evidenciou à retomada da concepção de afastamento e não intervenção Estatal, com o avanço de acirradas disputas comerciais entre grandes conglomerados produtivos mundiais, denotando-se a sobreposição da relação global sobre a local, trazendo o conceito de globalização.

Com o advento da globalização e a potencialização da instauração da hegemonia capitalista, desenvolvem-se conglomerados produtivos transnacionais, que reivindicam a adoção de políticas estatais cada vez menos intervencionistas, impactando diretamente nos processos produtivos e nas relações sociais.

No Brasil, de maneira mais específica, o avanço do neoliberalismo operacionalizouse a partir de 1990, com o governo do Presidente Fernando Collor (1990 a 1992), em que se implementou uma tentativa de afastamento/não intervenção do Estado, com um projeto de abertura econômica, mas em verdade, o que se seguiu foi uma imersão em crises institucionais, política e econômica (desestabilização), dentre outras áreas atingidas. Após o impedimento e afastamento de Fernando Collor do governo, e seguido ao governo interino de Itamar Franco (1992 a 1995), foi eleito para o governo Fernando Henrique Cardoso (1995 a 2003), que prosseguiu com a adoção de medidas econômicas iniciadas no governo interino (do qual participou como Ministro da Fazenda), em que privatizou diversas empresas e levou adiante a abertura de mercado. De forma mais recente, nos governos de Luis Inácio Lula da Silva (2003 a 2011) e Dilma Roussef (2011 a 2016), ambos do Partido dos Trabalhadores, ainda que se tenham implementado medidas sociais, não se pode assegurar que houve qualquer abandono as ideais neoliberais (inclusive, pelo prosseguimento do modelo/projeto econômico iniciado no governo de Fernando Henrique Cardoso).

Com o impedimento e afastamento de Dilma Roussef do governo, seguiu-se o governo interino de Michel Temer (2016 a 2019), em que foram implementadas medidas reformadoras, sob a justificada na necessidade de fomento da liberdade de comércio e 
mercado, como forma de obter-se a austeridade do país, mas que, em realidade são contrárias aos direitos sociais.

Neste sentido, em 15 de dezembro de 2016 foi publicada a Emenda Constitucional $n^{\circ}$ 95, de 15 de dezembro de 2016, que, em linhas gerais, congelou por 20 anos os gastos com despesas primárias, onde se inserem os investimentos em políticas públicas.

E mais, em 11 de novembro de 2017, entrou em vigor a Lei 13.467/2017, de 13 de julho de 2017, que impôs uma grande reforma na legislação trabalhista, sem que houvesse a realização de consultas públicas prévias às organizações de trabalhadores ${ }^{10}$, que dentre outras medidas enfraqueceu os sindicatos profissionais, com a retirada de uma arrecadação compulsória que advinha de contribuições, sem que se possibilitasse uma transição como forma de obtenção outras fontes de custeio por referidas instituições, sendo inegável o objetivo precípuo de combater a atividade sindical. Não se sustenta, o discurso de prevalência do negociado sobre o legislado, em favor do trabalhador, quando o que se implementou foram medidas de enfraquecimento de organizações de trabalhadores.

A partir do atual governo do Excelentíssimo presidente Jair Messias Bolsonaro (iniciado em $1^{\circ}$ de janeiro de 2019 ), o que se evidencia é a retomada, ostensiva, do projeto de Estado Neoliberal, no Brasil (Pós-neoliberalismo ostensivo brasileiro), sendo que de maneira imediata, e mais evidente, foram adotadas medidas contrários à garantia de direitos sociais, em especial ao trabalho, sob a justificativa de que uma das grandes causas para a retração da economia brasileira decorreria de um protecionismo exacerbado ao trabalhador, somado as amarras impostas ao empresariado.

Ainda que de maneira contida, em razão das limitações desta dissertação, não há como se deixar de se fazer referência ao fato de que, já no primeiro dia de mandato do atual governo federal, houve a extinção do Ministério do Trabalho, e a criação de uma Secretaria Especial integrada a estrutura do Ministério da Economia, com a divisão das atribuições entre os Ministérios da Justiça e Segurança Pública, Cidadania e da Economia, com maior concentração neste, inclusive, quanto à atividade de fiscalização, conforme Medida Provisória $\mathrm{n}^{\mathrm{o}} 870$, de $1^{\circ}$ de janeiro de 2019 , convertida na Lei $\mathrm{n}^{\circ} 13.844 / 2019$, de 18 de junho de 2019. Evidentemente que a subsunção da atividade fiscal do extinto Ministério do Trabalho àqueles que representam os interesses do capital contraria a necessidade de regulação estatal acerca da

\footnotetext{
10 Convenção 144 da Organização Internacional do Trabalho, promulgada pelo Decreto $n^{\circ} 2.518$ de 12 de março de 1998, que estabelece a necessidade de consultas tripartides prévias para qualquer alteração legislativa que afete as condições de trabalho.
} 
relação capital x trabalho, como fator determinante na manutenção da harmonia e paz na sociedade.

Como medida mais recente, destaca-se a edição da Medida Provisória 905, de 11 de novembro de 2019, que sem demonstrar qualquer urgência e relevância ${ }^{11}$, instituiu o contrato verde amarelo, sob a justificativa de criar novos postos de emprego para jovens entre 18 e 29 anos, mas que em verdade cria normas trabalhistas precárias (inclusive, retomando a, combatida, concepção de salário complessivo ${ }^{12}$ ) e objetiva, ainda, alterar ou extirpar outras normas trabalhistas já consolidadas.

$\mathrm{O}$ atual governo brasileiro, vem se tornando pródigo em governar por medidas provisórias, desprezando o papel do Parlamento e deixando de cumprir e respeitar a harmonia e independência entre os Poderes, constitucionalmente assegurada. ${ }^{13}$ Destaque-se aqui, também, a Medida Provisória 881, de 30 de abril de 2019, convertida na Lei nº 13.874/2019, de 20 de setembro de 2019, acerca da liberdade econômica.

Além de ser inadmissível qualquer descumprimento ou desrespeito a harmonia e independência entre os Poderes do Estado, é, também, inaceitável o qualquer desprezo por todo o histórico progresso do direito do trabalho (ao trabalho), e de todas as conquistas obtidas ao longo dos anos, que o elevaram ao patamar de um direito humano e fundamental, previsto na Constituição Federal de 1988 no capítulo dos direitos sociais (Capítulo II) e no título de direito e garantias fundamentais (Título II), sendo cláusula pétrea da precitada carta magna, como expressamente disposto no artigo $60, \S 4^{\circ}$, inciso IV, do diploma, não sendo, portanto, passível de alteração.

O que se tem observado, é a retórica retomada de discursos políticos corriqueiros, já adotado por inúmeros partidos, por longos períodos, sejam eles de direita ou de esquerda, que divergem, apenas, nas soluções apresentadas, para supostamente reduzir a falta de empregabilidade que se espraia pelo país, mas que, na realidade, em nada tem alterado os altos índices de desempregados, que já se vem mostrando em níveis alarmantes desde idos de 2014. Neste sentido, não há fato novo a motivar a edição de Medidas Provisórias, como tem

\footnotetext{
11 Artigo 62, caput, da Constituição da República Federativa do Brasil de 1988 - Em caso de relevância e urgência, o Presidente da República poderá adotar medidas provisórias, com força de lei, devendo submetê-las de imediato ao Congresso Nacional.

12 Salário complessivo são as determinadas importâncias ou percentuais recebidos, pelo trabalhador, para atendimento, de forma global, de vários direitos previstos em lei ou em contrato de trabalho.

${ }^{13}$ Artigo 2 ${ }^{\circ}$, Constituição da República Federativa do Brasil de 1988 - São Poderes da União, independentes e harmônicos entre si, o Legislativo, o Executivo e o Judiciário.
} 
se utilizado o atual governo brasileiro, sendo, também, que a situação de desemprego deve ser combatida pela retomada do progresso econômico e não pela precarização do trabalho.

$\mathrm{Na}$ realidade, o que se observa é o prosseguimento de medidas fundadas na doutrina neoliberal, ou em um pós-neoliberalismo (SADER, 1995), como projeto de flexibilização máxima de leis econômicas e trabalhistas, sob a justificativa abrir novos postos de trabalho ("inclusão de determinados segmentos em nichos de empregabilidade"), que em verdade, resultaram, apenas, na supressão de direitos e no empreendimento da prática governamental de fragilização de instituições públicas e privadas (com munus público) com atuação nas relações sociais e na promoção de políticas públicas.

Por fim, cabe aqui, ainda, uma imprescindível reflexão, no sentido de que se de fato a doutrina neoliberal - substrato da atual concepção de Pós-neoliberalismo ostensivo - obteve, até então, a desestatização que propagava, pregava e almejava, ou, em verdade, somente potencializou, de maneira expressiva, as desigualdades sociais e a tensão entre capital $\mathrm{x}$ trabalho, sob a justificativa, não alcançada, de crescimento e desenvolvimento econômico e social das nações.

\section{REFERÊNCIAS}

Bobbio, Norberto. Direito e esquerda; razões e significados de uma distinção política; tradução Marco Aurélio Nogueira. $3^{\text {a }}$ edição. Rio de Janeiro: Editora Unesp, 2012.

; Estado, governo, sociedade; por uma teoria da política; tradução Marco Aurélio Nogueira. Rio de Janeiro: Paz e Terra, 1987.

BONAVIDES, Paulo. Do Estado Liberal ao Estado Social. $8^{a}$ edição. São Paulo: Malheiros Editores, 2007.

BRASIL. Decreto $\mathbf{n}^{\mathbf{0}} \mathbf{2 . 5 1 8}$, de 12 de março de 1998 . Disponível em: http://www.planalto.gov.br/ccivil_03/decreto/D2518.htm. Acesso em: 20 nov. 2019. 
BRASIL. Emenda Constitucional $n^{0}$ 95, de 15 dezembro de 2016. Disponível em: http://www.planalto.gov.br/ccivil_03/constituicao/Emendas/Emc/emc95.htm. Acesso em: 20 nov. 2019.

BRASIL. Lei $\mathbf{n}^{\mathbf{0}}$ 13.467, de 13 de julho de 2017. Disponível em: http://www.planalto.gov.br/ccivil_03/_ato2015-2018/2017/lei/113467.htm. Acesso em: 20 nov. 2019.

BRASIL. Lei $\mathbf{n}^{\mathbf{0}}$ 13.844, de 18 de junho de 2019. Disponível em: http://www.planalto.gov.br/ccivil_03/_Ato2019-2022/2019/Lei/L13844.htm. Acesso em: 20 nov.2019.

BRASIL. Lei $\mathbf{n}^{0}$ 13.874, de 20 de setembro de 2019. Disponível em: http://www.planalto.gov.br/ccivil_03/_ato2019-2022/2019/Lei/L13874.htm. Acesso em: 20 de nov. 2019.

BRASIL. Medida Provisória $\mathbf{n}^{\mathbf{0}}$ 870, de $\mathbf{1}^{\mathbf{0}}$ de janeiro de 2019. Disponível em: http://www.planalto.gov.br/ccivil_03/_Ato2019-2022/2019/Mpv/mpv870.htm. Acesso em: 20 de nov. 2019.

BRASIL. Medida Provisória $\mathbf{n}^{\mathbf{0}}$ 881, de 30 de abril de 2019. Disponível em: http://www.planalto.gov.br/ccivil_03/_ato2019-2022/2019/Mpv/mpv881.htm. Acesso em: 20 de nov. 2019.

BRASIL. Medida Provisória $\mathbf{n}^{0}$ 905, de 11 de novembro de 2019. Disponível em: http://www.planalto.gov.br/ccivil_03/_Ato2019-2022/2019/Mpv/mpv905.htm. Acesso em: 20 de nov. 2019.

Constituição da República Federativa do Brasil: texto constitucional promulgado em 5 de outubro de 1988, compilado até a Emenda Constitucional no 101/2019. Brasília: Senado Federal, Coordenação de Edições Técnicas, 2019. 
IGREJA CATÓLICA; Papa (1978-2005: João Paulo II). Encíclica Laborem Exercens: sobre o trabalho humano no $90^{\circ}$ aniversário da Rerum Novarum. $14^{\mathrm{a}}$ ed. $1^{\mathrm{a}}$ reimpressão: Paulinas, 2012.

; Papa (1878-1903: Leão XIII). Encíclica Rerum Novarum: sobre a condição dos operários. Petrópolis: Vozes, 1991.

KEYNES, John Maynard. A teoria geral do emprego, do juro e da moeda. São Paulo: Nova cultural, 1996.

KREIN, José Dari. Debates contemporâneos economia social e do trabalho, 8: as relações de trabalho na era do neoliberalismo no Brasil. São Paulo: LTr, 2013.

MARX, Karl. A ideologia alemã; crítica da mais recente filosofia alemã em seus representantes Feuerbach, B. Bauer e Stirner / Karl Marx, Friedrich Engels; tradução de Milton Camargo Mota. Petrópolis: Vozes, 2019.

MORAES, Alexandre de. Direito Constitucional. 34. ed. São Paulo: Atlas, 2018.

NASCIMENTO, Amauri Mascaro. Curso de direito do trabalho: história e teoria geral do direito do trabalho, relações individuais e coletivas do trabalho. 19 ed., rev. e atual. São Paulo: Saraiva, 2004.

_ Iniciação ao direito do trabalho. 31. ed. São Paulo: LTr, 2005.

NOVAIS, Jorge Reis. Contributo para uma teoria do estado de direito. 1 ed. São Paulo: Editora Almeida, 2006.

PIOVESAN, Flávia. Direitos Humanos e o Direito Constitucional Internacional. 13 ${ }^{\mathrm{a}}$ ed. São Paulo: Saraiva, 2012.

SADER, Emir; GENTILI, Pablo. Pós-neoliberalismo: as políticas sociais e o Estado democrático. $5^{\text {a }}$ ed. Rio de Janeiro: Paz e Terra, 1995. 
SILVEIRA, Vladimir Oliveira da; ROCASOLANO, Maria Mendez. Direitos Humanos; conceitos, significados e funções. São Paulo: Saraiva, 2010.

SMITH, Adam. A riqueza das nações; tradução de Maria Teresa Lemos de Lima. $1^{\mathrm{a}}$ ed., $3^{\mathrm{a}}$ reimpressão. Curitiba: Juruá, 2015.

VIEIRA JUNIOR, Dicesar Beches. AS TRANSFORMAÇÕES DO (DIREITO DO) TRABALHO SOB A ÓTICA DO ESTADO LIBERAL E O ESTADO NEOLIBERAL. Revista Juridica, [S.1.], v. 2, n. 35, p. 276-296, nov. 2014. ISSN 2316-753X.

Disponível em: <http://revista.unicuritiba.edu.br/index.php/RevJur/article/view/949/654>. Acesso em: 20 abr. 2020. doi:http://dx.doi.org/10.21902/revistajur.2316-753X.v2i35.949. 